\title{
Produção e qualidade de sementes híbridas de berinjela em função do número de frutos por planta
}

\author{
Luana C Weber; Andrielle C Amaral-Lopes; Leonardo S Boiteux; Warley M Nascimento \\ Embrapa Hortaliças, C. Postal 218, 70351-970, Brasília-DF; warley.nascimento@embrapa.br
}

\begin{abstract}
RESUMO
A berinjela é uma espécie autógama, de flores perfeitas e que ainda não dispõe de sistema genético de macho-esterilidade para uso em escala comercial. Assim, a tecnologia de produção de sementes híbridas envolve emasculação e polinização manuais. No presente trabalho avaliou-se a produção e a qualidade de sementes híbridas de berinjela oriundas de plantas com diferentes números de frutos por planta, fecundados artificialmente. O experimento foi conduzido em campo de produção de sementes híbridas de berinjela 'Ciça' na Embrapa Hortaliças e os tratamentos corresponderam a diferentes números de frutos fecundados mantidos por planta $(6,9,12,15$ e 18). Foram selecionadas seis plantas/repetições para cada tratamento, nas quais os botões florais foram emasculados manualmente e realizados cruzamentos controlados. Foram avaliados 1) número de sementes por fruto; 2) número de sementes por planta; 3 ) massa de sementes por planta; 4) massa de 100 sementes; 5) teste padrão de germinação; 6) primeira contagem; 7) classificação do vigor; 8) envelhecimento acelerado; 9) teste de frio e 10) emergência de plântulas. O maior número de sementes por fruto foi obtido em plantas com seis frutos e o menor em plantas com 15 e 18 frutos. Plantas com 12, 15 e 18 frutos apresentaram maior número e massa de sementes por planta. Os tratamentos não diferiram quanto à massa de sementes, primeira contagem, germinação e plântulas normais. O teste de envelhecimento acelerado indicou que o período de $72 \mathrm{~h}$ se relaciona melhor com a germinação. O estabelecimento do limite de 12 frutos por planta está próximo do ideal, uma vez que permite a racionalização da mão-de-obra quanto ao número de interferências realizadas pelo produtor de sementes híbridas.
\end{abstract}

Palavras-chave: Solanum melongena, germinação, vigor, polinização.

\begin{abstract}
Yield and quality of hybrid eggplant seeds according to the number of fruits per plant

Eggplant is an autogamous species (perfect flowers) and with no genetic male-sterility system yet available for commercial use. Therefore, the technology of hybrid seed production is based upon hand emasculation and pollination. The present study aimed to evaluate if the yield and quality of hybrid seeds of eggplant is affected by the number of fruits kept in the plants after controlled pollination. Plants were selected within a production field of hybrid seeds of eggplant 'Ciça' and controlled crosses were performed. The treatments (six plants each) consisted of keeping 6, 9, 12, 15 and 18 fruits per plant after controlled hand emasculation and pollination of the flower buds. The following tests and determinations were performed 1) number of seeds per fruit; 2) number of seeds per plant; 3) seed weight per plant; 4) weight of 100 seeds; 5) germination; 6) first count; 7) vigor classification; 8) accelerated aging; 9) cold test and, 10) seedling emergence. The greatest number of seeds per fruit was obtained in plants with six fruits, and the lowest average in plants with 15 and 18 fruits. Seed production and seed weight per plant displayed similar results for all treatments. Plants with 12,15 and 18 fruits showed higher weight and number of seeds per plant. No statistical differences were observed for the treatments: seed weight, first count, germination and normal seedlings. In the accelerated aging test results indicated that the period of $72 \mathrm{~h}$ was more related to the germination test. It is suggested that using 12 fruits per plant would be the most efficient technology in terms of labor force management (hand emasculation and pollination).
\end{abstract}

Keywords: Solanum melongena, germination, vigor, pollination.

(Recebido para publicação em 1 de fevereiro de 2013; aceito em 10 de junho de 2013) (Received on February 1, 2013; accepted on June 10, 2013)

\begin{abstract}
$\mathrm{A}$ berinjela (Solanum melongena) é originária do sudoeste asiático e apresenta adaptação para cultivo nas regiões tropicais e subtropicais (Sekara et al., 2007). A temperatura diurna ótima para o crescimento e produção de frutos de berinjela está em torno de $25-35^{\circ} \mathrm{C}$ (Nascimento, 2004). No entanto, essa espécie é menos tolerante a baixas temperaturas quando comparada, por exemplo, ao tomateiro (S. lycopersicum) e não tolera geada (George, 2004).

Grande parte da área de cultivo de
\end{abstract}

berinjela no Brasil é feita atualmente com a utilização de variedades híbridas, refletindo uma antiga tendência a nível mundial (Ikuta, 1961; Shafeeq, 2005). $\mathrm{O}$ amplo uso de híbridos em berinjela se deve, principalmente, à frequência e intensidade da expressão da heterose na primeira geração dos cruzamentos entre linhagens endogâmicas. A heterose é a tendência da expressão fenotípica de indivíduos híbridos superar aquela observada pelos seus genitores, fenômeno geralmente observado nas gerações F1 em diversas espécies vegetais, incluindo a berinjela (Shafeeq, 2005). Nesse caso, a heterose pode ser utilizada com vantagem uma vez que o produto comercial apresenta valor elevado, o gasto com sementes por área é pequeno e a semente híbrida é produzida a preços relativamente baixos (Petrov et al., 1981).

Em berinjela, o aumento de produção de frutos comerciais dos híbridos em relação às linhagens parentais mais produtivas varia de 10 a $45 \%$, dependendo do cruzamento (Ikuta, 1961). Os 
híbridos, além de gerarem plantas mais vigorosas e mais produtivas, também tendem a apresentam maior estabilidade fenotípica ('homeostase'), mesmo em condições ambientais adversas (Noda, 1980).

O mercado consumidor brasileiro tem-se tornado cada vez mais exigente quanto à qualidade do produto, e quanto ao preço, o que tem levado os produtores à utilização de híbridos de alta produtividade, uniformidade e qualidade de frutos e, tolerância às doenças e pragas. No Brasil, a heterose tem sido explorada em berinjela desde a década de 1960, quando foi viabilizado o uso de um híbrido (denominado 'F-100') que substituiu, em escala comercial, as cultivares tradicionais (de polinização aberta) utilizadas até então (Ikuta, 1981). A utilização comercial por mais de um quarto de século do híbrido 'F-100', abriu espaço para a introdução de novos materiais que dominam o mercado brasileiro atual, tais como 'Nápoli', 'Super F-100', 'F-1000' e 'Ciça' (Antonini et al., 2002). O híbrido 'Ciça' caracteriza-se por apresentar resistência à antracnose causada por Colletotrichum gloeosporioides e à podridão causada por Phomopsis vexans, sendo atualmente um dos materiais mais utilizado devido sua grande produtividade, rusticidade, uniformidade e padronização das plantas e frutos, além da maior adaptação a diferentes condições edafoclimáticas observadas nas diferentes regiões do Brasil.

A berinjela é uma espécie diplóide, preferencialmente autógama, auto-compatível e com flores perfeitas (hermafrodita) (Sekara et al., 2007). Contudo, dependendo das condições ambientais e da presença de insetos polinizadores, pode apresentar taxas variáveis de polinização cruzada (George, 2004; Nascimento, 2004). A berinjela apresenta dicogamia do tipo protoginia quando o estigma alcança a maturidade antes da antera, exigindo ajustes na época de semeadura, especialmente para a produção de sementes híbridas (Petrov et al., 1981). Para essa espécie, os produtores de sementes ainda não dispõem de sistemas genéticos de macho-esterilidade para uso em escala comercial, embora esforços de pesquisas estejam sendo conduzidos nessa direção
(Isshiki \& Yoshida, 2002). Dessa forma, a tecnologia de produção de sementes híbridas ainda envolve a emasculação e polinização manuais controladas (George, 2004).

Embora laboriosa, a produção manual de sementes híbridas de berinjela é favorecida pelo grande tamanho dos botões florais, facilitando o processo de emasculação e polinização; elevado número de flores por planta; abundância e fácil coleta de pólen; maior proteção do pólen pelo sistema de deiscência poricida; amplo período de florescimento e elevado número de sementes por fruto (Ikuta, 1981).

Nas duas últimas décadas, ocorreu uma grande expansão no uso de híbridos que oferecem múltiplos atributos de interesse em um único genótipo e maior agregação de valor à semente (Giordano et al., 2003). As mudanças na economia induzidas pela globalização têm exigido do setor agrícola maior eficiência técnica e econômica na condução de todas as atividades, incluindo o setor de produção de sementes. Neste contexto, a busca de competitividade e rentabilidade da produção de sementes híbridas de berinjela representa uma das metas prioritárias para a cadeia agrícola. No entanto, diferentes aspectos do sistema ainda necessitam de otimização (George, 2004), considerando que ainda não é plenamente conhecido o número ideal de frutos resultante de polinização controlada que deve ser mantido em uma planta de berinjela visando produzir sementes de elevada qualidade genética e fisiológica. Neste contexto, o presente trabalho representou um estudo visando otimizar a produção e a qualidade de sementes híbridas de berinjela oriundas de plantas com diferentes números de frutos.

\section{MATERIAL E MÉTODOS}

Todas as etapas deste trabalho foram realizadas nas instalações da Embrapa Hortaliças, Brasília-DF, de junho de 2009 a junho de 2010. Em um campo de produção de sementes híbridas de berinjela 'Ciça' foram obtidas ao acaso seis plantas/repetição para cada tratamento, onde se variou o número de frutos por planta: $6,9,12,15$ e 18 . Os botões florais foram emasculados manualmente através da abertura da flor com uma pinça e as pétalas e os estames removidos. As flores da linhagem masculina foram recolhidas com algumas horas de antecedência e colocadas em local seco e fresco, para facilitar o desprendimento do pólen. O pólen foi extraído das flores por vibração, colocado em tubos plásticos de micro-centrífuga e conservado a $5^{\circ} \mathrm{C}$. O estigma da flor recém-emasculada foi então, polinizado por volta das $10 \mathrm{~h}$, para melhorar a eficiência de fertilização. Em seguida, a parte feminina restante (ovário, estilete e estigma) foi protegida por um cartucho de papel alumínio. Todos os cruzamentos controlados foram etiquetados, indicando a data do cruzamento. As flores e os frutos não oriundos dos cruzamentos controlados foram eliminados, para que a planta fosse conduzida de acordo com a quantidade de frutos estipulada a priori em cada tratamento. Após 60 dias da data de cruzamento, os frutos foram colhidos e colocados em repouso por 10 dias em um ambiente protegido e arejado. Após este período, as sementes foram extraídas por processo manual, obedecendo ao seguinte procedimento: os frutos foram batidos com bastão de madeira roliça para soltar as sementes no seu interior e facilitar a sua remoção. Em seguida, os frutos foram abertos dentro de um recipiente com água e as sementes foram separadas manualmente da polpa, migrando para o fundo do recipiente. A polpa sem sementes foi descartada e as sementes lavadas, drenadas e espalhadas em finas camadas sobre peneira de tela de "nylon" para secagem. As sementes permaneceram em câmara de pré-secagem a $32^{\circ} \mathrm{C}$ por 24 horas.

Após esse processo, as sementes foram submetidas aos seguintes testes e determinações: 1) Número médio de sementes/fruto: Foi avaliado através da contagem das sementes de um fruto de cada planta/repetição de cada tratamento; 2) Número médio de sementes/ planta: Foi realizado através da contagem de sementes existentes em cada repetição de cada tratamento; 3) Massa de sementes/planta: As sementes de cada repetição foram pesadas em balança analítica com três casas decimais, para 
determinação da produção de sementes por planta; 4) Massa de 100 sementes: Efetuada com seis repetições de 100 sementes, em balança analítica com precisão de três casas decimais, sendo os resultados expressos em gramas; 5) Teste padrão de germinação: Seis repetições de cada tratamento ( 50 sementes recém-colhidas) foram colocadas para germinar em caixas acrílicas do tipo gerbox. As sementes foram acondicionadas sob duas folhas de papel de germinação do tipo 'mata-borrão', previamente umedecido com quantidade de água destilada equivalente a 2,5 vezes a massa do substrato seco e colocadas em germinador a $20-30^{\circ} \mathrm{C}$ de acordo com as Regras para Análise de Sementes (Brasil, 2009). As avaliações da porcentagem de sementes com protrusão da raiz primária foram realizadas aos sete e quatorze dias após a instalação do teste; 6) Primeira contagem: Conduzido simultaneamente ao teste de germinação, constituiu do registro da porcentagem de sementes com protrusão da raiz primária obtida no sétimo dia após o início do teste. Após dois meses de armazenamento em câmara fria $\left(10^{\circ} \mathrm{C} ; 45 \%\right.$ UR) e acondicionadas em embalagens aluminizadas, as sementes foram novamente submetidas ao teste padrão de germinação e primeira contagem, conforme metodologia descrita; sendo avaliada a porcentagem de sementes com protrusão da raiz primária e formação de plântulas normais; 7) Vigor: Aos quatorze dias após a semeadura do teste de germinação classificou-se o vigor das plântulas em normais 'fortes' (vigorosas) e normais 'fracas' (pouco vigorosas); 8) Envelhecimento acelerado (de acordo com França et al. 2007): Amostras com 250 sementes de cada tratamento foram uniformemente distribuídas sobre tela de alumínio, fixada em caixas plásticas tipo gerbox, contendo ao fundo, $40 \mathrm{~mL}$ de água destilada (método tradicional). As caixas contendo as sementes foram fechadas e mantidas a $41^{\circ} \mathrm{C}$, por períodos de 24 , 48 e 72 horas. Em seguida, as sementes foram submetidas ao teste de germinação, conforme descrito anteriormente; 9) Teste de frio: Para cada tratamento foram utilizadas seis repetições com 50 sementes em caixa gerbox, sob duas folhas de papel 'mata-borrão' e umedecidas com água destilada. Após, foram incubados em temperatura de $10^{\circ} \mathrm{C}$ durante sete dias e, em seguida, os gerbox foram transferidos para o germinador na temperatura ótima de germinação (20$30^{\circ} \mathrm{C}$ ), onde permaneceram por quatorze dias. O resultado foi computado pela porcentagem de plântulas normais e 10) Emergência de plântulas: Foram utilizadas seis repetições de 50 sementes, as quais foram semeadas em bandejas multicelulares de poliestireno expandido (isopor) com 200 células, contendo substrato comercial (Plantmax ${ }^{\circledR}$ ) e colocadas para germinar em condições de casa de vegetação. A avaliação foi realizada 21 dias após a semeadura, e os resultados foram expressos em porcentagem. O delineamento utilizado para todas as análises foi inteiramente casualizado. Os dados foram submetidos à análise de variância e a comparação de médias foi procedida pelo teste de Tukey a $5 \%$ de probabilidade.

\section{RESULTADOS E DISCUSSÃO}

A produção média de sementes híbridas obtida com a berinjela 'Ciça' tem sido entre 6 e 8 gramas por fruto (Nascimento, 2004). Observou-se no presente estudo que o número médio de sementes por fruto variou de 748 a 2.170 sementes (entre 5 e 10 gramas), ou seja, dentro de uma faixa de amplitude próxima ao observado anteriormente para esse híbrido. O maior número de sementes por fruto foi alcançado em plantas com seis frutos (2.170) e o menor número de sementes por fruto foi verificado naquelas com 15 e 18 frutos (790 e 748, respectivamente) (Tabela 1). Dados reportados anteriormente para outras cultivares indicam que berinjelas provenientes de polinização cruzada produzem em torno de 688 sementes por frutos (Noda, 1980). No presente trabalho, os resultados encontrados para o híbrido 'Ciça' mostraram que em todos os tratamentos as médias foram superiores a este número, evidenciando uma maior produção da linhagem maternal ou mesmo do híbrido.

A produção de sementes por planta e a massa de sementes por planta apresentaram comportamento semelhante entre os diferentes tratamentos. Plantas com 9, 12, 15 e 18 frutos não diferiram estatisticamente entre si, com valores de maior número e massa de sementes por planta. Já o tratamento com seis frutos por planta apresentou-se estatisticamente inferior aos demais, não diferindo apenas do tratamento onde manteve-se 9 frutos por planta (Tabela 1). Dessa

Tabela 1. Número médio de sementes por fruto e por planta, massa de sementes por planta e massa de cem sementes híbridas de berinjela (Solanum melongena) provenientes de diferentes números de frutos mantidos por planta (average number of seeds per fruit and per plant, seed mass per plant and seed weight of hybrid eggplant from different number of fruits crossed per plant). Brasília, Embrapa Hortaliças, 2010.

\begin{tabular}{lcccc}
\hline Frutos/planta $\left(\mathbf{n}^{\mathbf{0}}\right)$ & $\begin{array}{c}\text { Sementes/fruto } \\
\left(\mathbf{n}^{\mathbf{0}} \text { médio) }\right.\end{array}$ & $\begin{array}{c}\text { Sementes/planta } \\
\left(\mathbf{n}^{\mathbf{0}} \text { médio) }\right.\end{array}$ & $\begin{array}{c}\text { Massa de sementes/planta } \\
\mathbf{( g )}\end{array}$ & $\begin{array}{c}\text { Massa de 100 sementes } \\
(\mathbf{g})\end{array}$ \\
\hline 6 & $2.170^{1} \mathrm{a}$ & $10.507 \mathrm{~b}$ & $61,01 \mathrm{~b}$ & $0,577 \mathrm{a}$ \\
9 & $1.848 \mathrm{~b}$ & $14.138 \mathrm{ab}$ & $83,38 \mathrm{ab}$ & $0,580 \mathrm{a}$ \\
12 & $1.028 \mathrm{c}$ & $17.144 \mathrm{a}$ & $93,19 \mathrm{a}$ & $0,543 \mathrm{a}$ \\
15 & $790 \mathrm{~d}$ & $17.814 \mathrm{a}$ & $100,99 \mathrm{a}$ & $0,568 \mathrm{a}$ \\
18 & $748 \mathrm{~d}$ & $17.122 \mathrm{a}$ & $97,17 \mathrm{a}$ & $0,570 \mathrm{a}$ \\
\hline $\mathrm{CV}(\%)$ & 2,58 & 20,55 & 20,84 & 4,07 \\
\hline
\end{tabular}

${ }^{1}$ Médias seguidas pela mesma letra na coluna, não diferem entre si, Tukey, $5 \%$ (means followed by the same letter in the columns did not differ from each other, Tukey, $\mathrm{p}<0.05$ ). 
forma, o tratamento com seis frutos por planta apresentou a maior produção de sementes por fruto; no entanto, mostrou-se inferior aos demais quanto ao número médio e peso de sementes por planta, ou seja, as plantas conduzidas com maior número de frutos apresentaram maior produção de sementes. Por mais que as plantas com menor número de frutos tenham proporcionado a obtenção do maior número de sementes, a condução das plantas com somente seis frutos pode não ser interessante no final do processo produtivo para a produção de sementes, considerando-se o número médio ou o peso de sementes/planta.

Não houve diferença estatística em relação à massa de 100 sementes, ocorrendo uma variação de 0,543 a 0,580 gramas (Tabela 1 ). Na avaliação da germinação das sementes recém colhidas, nos testes de primeira contagem e de germinação, onde foi considerada germinada a semente que apresentou a protrusão da radícula, não houve diferenças significativas entre os cinco diferentes tratamentos, tanto para a primeira contagem quanto para a germinação (dados não apresentados). Da mesma forma, na avaliação das sementes após o período de 2 meses de armazenamento, não houve diferença estatística entre os tratamentos descritos para a germinação das sementes para os dados de porcentagem de germinação na primeira contagem e porcentagem de plântulas normais (dados não apresentados). No entanto, numericamente, todos os cinco tratamentos apresentaram na avaliação das sementes armazenadas por 2 meses, porcentagem de germinação no teste de primeira contagem superior aos resultados da avaliação logo após a colheita; isto pode ter acontecido devido a uma possível dormência primária presente nas sementes, sendo que esta pode ter sido quebrada em função do tempo de armazenamento (dois meses). Bhéring et al. (2000), trabalhando com sementes de pepino, verificaram que o teste de primeira contagem de germinação pode ser utilizado para obtenção de informações preliminares sobre o vigor de lotes de sementes dessa espécie. O teste de primeira contagem de germinação, muitas vezes, expressa melhor as diferenças de velocidade de

Tabela 2. Plântulas normais (\%) no teste de envelhecimento acelerado (EA) em sementes híbridas de berinjela (Solanum melongena) provenientes de diferentes números de frutos mantidos por planta (accelerated aging test of hybrid eggplant from different number of fruits crossed per plant). Brasília, Embrapa Hortaliças, 2010.

\begin{tabular}{lccc}
\hline Frutos/planta $\left(\mathbf{n}^{\mathbf{0}}\right)$ & EA (24 horas) & EA (48 horas) & EA (72 horas) \\
\hline 6 & $39^{1} \mathrm{Cb}$ & $58 \mathrm{Aa}$ & $41 \mathrm{Bb}$ \\
9 & $47 \mathrm{Cb}$ & $55 \mathrm{Ba}$ & $73 \mathrm{Aa}$ \\
12 & $79 \mathrm{Aa}$ & $68 \mathrm{Ca}$ & $69 \mathrm{Ba}$ \\
15 & $68 \mathrm{Bab}$ & $72 \mathrm{Aa}$ & $72 \mathrm{Aa}$ \\
18 & $67 \mathrm{Cab}$ & $71 \mathrm{Ba}$ & $75 \mathrm{Aa}$ \\
\hline $\mathrm{CV}(\%)$ & 28,75 & 17,76 & 24,17 \\
\hline
\end{tabular}

${ }^{1}$ Médias seguidas pela mesma letra maiúscula na linha e minúscula na coluna não diferem entre si, Tukey, $5 \%$ (means followed by same uppercase letters in the rows and same lowercase letters in the columns did not differ from each other, Tukey, $\mathrm{p}<0.05$ ).

Tabela 3. Plântulas normais $(\mathrm{PN})$ após teste de frio $\left(10^{\circ} \mathrm{C}\right)$ e emergência de plântulas (aos 21 dias) oriundas de sementes híbridas de berinjela (Solanum melongena) provenientes de diferentes números de frutos mantidos por planta (normal seedling frequency (PN) after cold test of hybrid eggplant from different number of fruits crossed per plant). Brasília, Embrapa Hortaliças, 2010.

\begin{tabular}{lcc}
\hline Frutos/planta $\left(\mathbf{n}^{\mathbf{0}}\right)$ & PN (\%) teste de frio & PN (\%) aos 21 dias \\
\hline 6 & $23^{1} \mathrm{~b}$ & $83 \mathrm{~b}$ \\
9 & $29 \mathrm{~b}$ & $93 \mathrm{ab}$ \\
12 & $62 \mathrm{a}$ & $91 \mathrm{ab}$ \\
15 & $37 \mathrm{ab}$ & $98 \mathrm{a}$ \\
18 & $43 \mathrm{ab}$ & $89 \mathrm{ab}$ \\
\hline $\mathrm{CV}(\%)$ & 39,49 & 8,05 \\
\hline
\end{tabular}

${ }^{1}$ Médias seguidas pela mesma letra na coluna não diferem entre si, Tukey, $5 \%$ (means followed by same letters in the columns did not differ from each other, Tukey, $\mathrm{p}<0.05$ ).

germinação entre lotes. Além disso, esse teste é menos trabalhoso que o índice de velocidade de germinação, podendo ser conduzido simultaneamente com o teste de germinação.

Em relação à classificação do vigor, verificou-se que todos os tratamentos apresentaram alto índice de plântulas normais vigorosas, não havendo diferença entre eles (dados não apresentados). Vale salientar que a porcentagem de germinação mínima aceita para comercialização de sementes de berinjela no país é de 70\% (Portaria Ministerial $\mathrm{n}^{\circ} 457$, de 18 de dezembro de 1986). Dessa forma, observa-se que os lotes oriundos dos tratamentos com 6 e 9 frutos por planta não atingiram o padrão mínimo necessário para comercialização de sementes (dados não apresentados).

Resultados elevados de germinação não significam necessariamente que os lotes possuem vigor mais elevado, uma vez que o teste de germinação é conduzido em condições favoráveis de temperatura, umidade e luminosidade, permitindo ao lote expressar o potencial máximo para produzir plântulas normais. No teste de envelhecimento acelerado (Tabela 2), os tratamentos com 6 frutos por planta (conduzido durante 24 e 72 horas) e 9 frutos por planta (conduzido por 24 horas) apresentaram os menores valores de germinação. Os tratamentos com 9 frutos por planta ( 72 horas), 12 frutos por planta (24 horas), 15 frutos ( 48 e 72 horas) e 18 frutos ( 48 e 72 horas) apresentaram germinação acima de $70 \%$, considerada mínima para a espécie em estudo. Esse grupo representou os tratamentos com maior resistência ao teste de envelhecimento acelerado. Não foi observada diferença estatística entre os diferentes tratamentos $(6,9,12,15$ e 18 frutos por planta) 
utilizando-se o período de envelhecimento por 48 horas.

A análise dos resultados obtidos, pelo procedimento tradicional, indicou que o período de 72 horas, a $41^{\circ} \mathrm{C}$, mostrou maior relação com os testes de germinação, especialmente quanto à identificação de lotes de potencial fisiológico elevado. Resultados nesse sentido também foram encontrados por Panobianco \& Marcos-Filho (2001) em sementes de tomate, quando se utilizou a mesma combinação. No entanto, no presente trabalho, o período de envelhecimento de 24 horas foi capaz de separar os tratamentos em três níveis de vigor: os tratamentos com 6 e 9 frutos (baixo vigor), os tratamentos com $15 \mathrm{e}$ 18 frutos (intermediários) e o tratamento com 12 frutos (alto vigor). Esse teste, embora não totalmente padronizado para as diferentes espécies, é considerado como importante teste na avaliação da qualidade fisiológica de sementes (International Seed Testing Association, 1981). A utilidade do teste de envelhecimento acelerado em detectar diferenças na qualidade de sementes foi observada por Caliari \& Marcos-Filho (1990). Mesmo assim, apesar de vários estudos terem sido conduzidos, ainda não existe um consenso entre os pesquisadores, quanto aos períodos mais adequados na execução do teste de envelhecimento acelerado para sementes de diversas espécies de importância econômica. Dentro desse contexto, trabalhos foram desenvolvidos com sementes de hortaliças envolvendo diferentes períodos e temperaturas, entre os quais se destacam os trabalhos com pepino, $41^{\circ} \mathrm{C}$ por 48 $\mathrm{h}$ (Bhéring et al., 2000) e tomate, $41^{\circ} \mathrm{C}$ por $72 \mathrm{~h}$ (Panobianco \& Marcos-Filho, 2001). Ressalta-se a importância do uso de mais um teste para determinar o vigor dos lotes de sementes devido à influência dos métodos adotados e uso de situações específicas de estresse para estimar o comportamento relativo dos lotes em campo (Carvalho \& Nakagawa, 2000).

O teste de frio a $10^{\circ} \mathrm{C}$ é realizado para avaliar o vigor de sementes que serão plantadas em condições de baixas temperaturas; comumente utilizado para milho, pode ser realizado em outras espécies. Verifica-se que o tratamento com 12 frutos por planta destacou-se dos demais tratamentos, apresentando porcentagem superior de germinação de plântulas normais (62\%) (Tabela 3). Por sua vez, os tratamentos com 6 e 9 frutos por planta apresentaram porcentagem de germinação de plântulas normais inferior aos demais tratamentos, 23 e $29 \%$ respectivamente. Os tratamentos 15 e 18 frutos por planta não diferiram estatisticamente dos demais tratamentos (Tabela 3). Observa-se que este teste permitiu a estratificação dos tratamentos à semelhança do teste de envelhecimento acelerado por 24 horas, ou seja, os tratamentos com 6 e 9 frutos apresentaram sementes de baixo vigor, os tratamentos com 15 e 18 frutos mostraram vigor intermediário e o tratamento com 12 frutos apresentou-se como de alto vigor. Deve-se salientar que o monitoramento da temperatura durante o teste requer atenção especial, para que sejam obtidos resultados consistentes.

Em campo a porcentagem de emergência de plântulas foi diferente quanto ao resultado obtido em laboratório. $\mathrm{O}$ tratamento com seis frutos por planta mais uma vez apresentou porcentagem de plântulas normais inferior e o tratamento com 15 frutos por planta apresentou porcentagem de plântulas normais superior aos demais tratamentos quando avaliados aos 21 dias após a semeadura (Tabela 3).

A temperatura ideal para a germinação dessa espécie é em torno de 20 a $30^{\circ} \mathrm{C}$. Com isso, em muitos dos casos, a porcentagem de germinação indicada no rótulo da embalagem de um determinado lote de sementes, poderá não corresponder à emergência das plântulas em campo obtida pelo produtor. Isto se deve ao fato de que o teste de germinação é realizado em laboratório, sob condições ótimas de ambiente, principalmente temperatura e disponibilidade de água. Assim, se a temperatura do solo por ocasião da semeadura não for aquela ideal para a espécie, a germinação poderá ser diferente (geralmente menor) daquela indicada na etiqueta da embalagem (Nascimento \& Lima, 2008). No caso específico da berinjela, onde as mudas são produzidas em bandejas, sob cultivo protegido, para posterior transplantio, cuidados com a temperatura durante a germinação devem ser tomados visando assim a maximização da germinação e emergência das plântulas.

Os resultados obtidos indicam que os tratamentos com 6 e 9 frutos por planta não são desejáveis para um campo de produção de sementes, uma vez que o rendimento por área considerada fica abaixo do desejado. Quando se observa o resultado obtido com 12, 15 e 18 frutos por planta verifica-se que o rendimento melhora significativamente, quando comparado ao resultado anterior (6 e 9 frutos/planta), tendo todos os tratamentos apresentado a qualidade desejada.

Em suma, os resultados indicam e/ou confirmam que, quanto maior o número de frutos na planta, menor será a produção de sementes de cada fruto. Por sua vez, a germinação não é afetada independente do número de frutos por planta. Em termos de envelhecimento acelerado, a análise dos resultados obtidos, pelo procedimento tradicional, indicou que o período de 72 horas, a $41^{\circ} \mathrm{C}$, mostrou-se mais relacionado com os testes de germinação, especialmente quanto à identificação de lotes de potencial fisiológico elevado. O número de 12 frutos fecundados mantidos por planta resultou em sementes mais resistentes à emergência de plântulas normais quando expostas a baixa temperatura. A adoção desse procedimento pode ter, portanto, consequências no desempenho comercial do híbrido em condições ambientais adversas. No que diz respeito às emasculações, o estabelecimento do limite de 12 frutos fecundados mantidos por planta está próximo do ideal, uma vez que permite a racionalização da mão-de-obra em termos do número de interferências realizadas pelo produtor de sementes híbridas.

\section{AGRADECIMENTOS}

Warley Marcos Nascimento e Leonardo S. Boiteux são Bolsistas de Produtividade em Pesquisa do CNPq/MCT.

\section{REFERÊNCIAS}

ANTONINI ACC; ROBLES WGR; NETO JT; KLUGE RA. 2002. Capacidade produtiva de cultivares de berinjela. Horticultura Brasileira 20: 646-648. 
BHÉRING MC; DIAS DCFS; GOMES JM; BARROS DI. 2000. Métodos para avaliação do vigor de sementes de pepino. Revista Brasileira de Sementes 22: 171-175.

BRASIL. 2009. Ministério da Agricultura, Pecuária e Abastecimento. Regras para Análise de Sementes. Secretaria de Defesa Agropecuária. Brasília: MAPA/ACS. 399p.

CALIARI MF; MARCOS-FILHO J. 1990. Comparação entre métodos para a avaliação da qualidade fisiológica de sementes de ervilha (Pisum sativum L.). Revista Brasileira de Sementes 12: 52-75.

CARVALHO NM; NAKAGAWA J. 2000 Sementes: ciências, tecnologia e produção. 4ed. Jaboticabal: FUNEP, 588p.

FRANÇA LV; NASCIMENTO, WM; FREITAS RA. 2007. Accelerated aging test on eggplant seeds. In: $28 \mathrm{TH}$ ISTA CONGRESS/ XV CONGRESSO BRASILEIRO DE SEMENTES, 2007, Foz de Iguaçu. Anais... Foz de Iguaçu: Abrates, 118p.

GEORGE RAT. 2004. Vegetable Seed Production. $2^{\text {nd }}$ ed. CABI, Wallinford, United Kingdom, $328 \mathrm{p}$.
GIORDANO LB; ARAGÃO FAS; BOITEUX LS. 2003. Melhoramento genético do tomateiro, Informe Agropecuário 24: 43-57.

INTERNATIONAL SEED TESTING ASSOCIATION. 1981. Handbook of vigour test methods. Zurich, Switzerland. 72p.

ISSHIKI S; YOSHIDA S. 2002. Characteristics of the cytoplasmic male sterility in the eggplant (Solanum melongena L.) carrying the cytoplasm of $S$. violaceum Ort. Bulletin Faculty Agricultural of Saga Univerity 87: 87-93.

IKUTA H. 1961. Vigor híbrido da geração F1 em berinjela (Solanum melongena L.). Piracicaba: ESALQ. 41p. (Tese doutorado).

IKUTA H. 1981. Produção de sementes híbridas F1 em berinjela. In : $1^{\circ}$ CURSO DE PRODUÇÃO E TECNOLOGIA DE SEMENTES DE HORTALIÇAS, Brasília. Palestras...Brasília: EMBRAPA-CNPH, p.191-192.

NASCIMENTO WM. 2004. Produção de sementes de berinjela. In: IV CURSO SOBRE TECNOLOGIA DE PRODUÇÃO DE SEMENTES DE HORTALIÇAS, Brasília. Palestras... Brasília: Embrapa Hortaliças,
CD-ROM.

NASCIMENTO WM; LIMA LB. 2008. Condicionamento osmótico de sementes de berinjela visando a germinação sob temperaturas baixas. Revista Brasileira de Sementes 30: 224-227.

NODAH. 1980. Critérios de avaliação de progênies de irmãos germanos interpopulacionais em berinjela (Solanum melongena L.). Piracicaba: ESALQ/USP. 1980. 91p. (Tese mestrado).

PANOBIANCO M; MARCOS-FILHO J. 2001. Envelhecimento acelerado e deterioração controlada em sementes de tomate. Scientia Agricola 58: 525-531.

PETROV HR; DOIKOVA M; POPOVA D. 1981. Studies on the quality of eggplant seed. Acta Horticulturae 111: 273-280.

SEKARA A; CEBULA S; KUNICK E. 2007. Cultivated eggplants - origin, breeding objectives and genetic resources, a review. Folia Horticulturae 19: 97-114.

SHAFEEQ A. 2005. Heterosis and combining ability studies in brinjal (Solanum melongena L.). Dharwad, India: University of Agricultural Sciences. 103 p. (Tese mestrado). 